\title{
EÇA DE QUEIRÓS POR ANTÓNIO JOSÉ SARAIVA: IDEIAS E IDEAIS
}

\author{
Antonio Augusto Nery ${ }^{1}$
}

\begin{abstract}
RESUMO: António José Saraiva (1917-1993) foi um profícuo intelectual português. Dentre suas produções estão as críticas literárias sobre as obras de diversos autores portugueses, entre eles, Eça de Queirós. Por muito tempo, o seu livro As ideias de Eça de Queiroz (1946) foi tido pelos estudiosos, críticos e leitores em geral da obra queirosiana como uma importante análise dos textos de Eça. Saraiva busca mostrar o quanto o autor de O Primo Basílio e Os Maias fora revolucionário em sua carreira de escritor. Neste trabalho procuraremos analisar as teses de Saraiva, contidas em As ideias... principalmente aquelas voltadas para a ficção inicial de Eça, os contos e crônicas escritos entre 1866 e 1867 e coligidos postumamente no volume Prosas bárbaras, publicado em 1903. Pretendemos demonstrar que, em sua análise, Saraiva atém-se mais àquelas obras de Eça nas quais as críticas ferinas à sociedade portuguesa são mais nítidas e avultantes, enquanto as que estão fora do escopo da crítica social são menos valorizadas. Ao nosso ver, essa opção de Saraiva ajudou a criar a ideia, manifestada em outras diversas leituras críticas tradicionalmente aceitas sobre a obra de Eça de Queirós, de que o escritor teria de um lado obras nas quais foi um crítico atroz e "revolucionário" e em outras de que teria sido um condescendente, apaziguado com o próprio país.
\end{abstract}

PALAVRAS - CHAVE: António José Saraiva, Eça de Queirós, Prosas bárbaras

ABSTRACT: António José Saraiva (1917-1993) was a productive Portuguese intellectual, and some of his most relevant work includes the criticism on important Portuguese writers, such as Eça de Queirós. For a long period, his book As ideias de Eça de Queirós (1946), in which he depicted the revolutionary side of Eça, was highly considered in the literary circles. In this article, we intend to analyze Saraiva's ideas, especially the ones concentrated on Eça de Queirós 's early work. Our intention is to demonstrate that Saraiva dedicated his attention to those books or pieces in which Eça's criticism on society was most vivid and harsh, while the ones which did not provide such a strong view on Portugal social situation were disregarded. It is our belief that Saraiva's option led to the general acceptance about Eça de Queirós's work having two sides: one in which he was a "relovutionary" author, and another in which he consented with the country's situation.

KEY-WORDS: António José Saraiva, Eça de Queiros, Prosas bárbaras.

António José Saraiva (1917-1993) foi um intelectual múltiplo: professor, escritor, ensaísta, crítico e historiador da literatura portuguesa. Como professor universitário, lecionou em diversas instituições de Portugal e ficou muito conhecido por sua participação no PCP (Partido Comunista de Portugal), sendo militante ativo e forte opositor do regime de Salazar. Devido à sua filiação política, em 1960 ficou exilado na França, onde foi professor, tendo também lecionado na Holanda. Pôde regressar a Portugal somente em 1974 quando passou a trabalhar na Universidade Nova de Lisboa e, posteriormente, na Universidade de Lisboa até o ano de 1993, quando faleceu².

\footnotetext{
${ }^{1}$ Doutorando em Letras (Literatura Portuguesa) pela Universidade de São Paulo (USP).

2 Cf. MESQUITA, João Miguel de Carvalho. História da Cultura - António José Saraiva. In $<$ www.citi.pt/cultura/historia_cultura/a_j_saraiva/index.html $>$. Acesso em 11/07/2008.
} 
Entre suas investidas na área de crítica literária, Saraiva escreveu, em $1946^{3}$, o livro as Ideias de Eça de Queiroz no qual busca analisar a obra completa de Eça sob a perspectiva da crítica social desenvolvida por ele em muitas de suas obras. Dentre os inúmeros temas desenvolvidos por Eça ao longo de seus textos, Saraiva elegeu alguns para comprovar suas teses acerca dos ideais do escritor, entre eles está a temática religiosa. Para Saraiva toda a manifestação mística presente nas obras de Eça resume-se na problemática da "Natureza". A Natureza estaria presente na literatura queirosiana personificada através de alguns temas básicos, entre os quais o panteísmo, o antropomorfismo e o humanismo seriam os mais corriqueiros.

A crença no panteísmo consistia na concepção de uma alma que estaria presente em todo o ser vivo e que a todo o momento aspiraria à liberdade. $\mathrm{O}$ universo, cheio de almas, levava também a uma visão politeísta dos elementos naturais. Tudo, desde árvores, flores e rochas, teria sua alma, por isso a ideia de uma força vital ou de uma alma universal desenvolvendo-se na natureza seria constantemente veiculada na ficção de Eça de Queirós.

Eça teria adquirido tal concepção acerca da religião durante o período de estudos em Coimbra, onde tivera contato com várias teorias que propunham a existência de Deus dentro da natureza e do homem. A revelação divina dava-se por uma consciência progressiva do ser humano. Para Saraiva, a maioria dos pensadores, que naqueles idos seduziam os estudantes de Coimbra, concordava com essa ideia acerca da Natureza:

Todos eles, com efeito, acreditavam que a história da Natureza e a história do homem documentam o desenvolvimento e o progresso de uma força imanente - aquela aspiração à liberdade que, segundo Antero, já existe na pedra e que no Homem se torna consciente. A história da Natureza é por isso o prefácio da história do Homem - a luta pela liberdade, o esforço para a realização do reino do Homem na terra, que os místicos sonhavam como reino de Deus no céu. No fundo, portanto, do panteísmo desta geração e dos seus mestres há um humanismo ${ }^{4}$.

Tal interpretação materialista, que está muito vinculada com as ideias de Hegel (1770-1831), parece não servir apenas para explicar o fenômeno religioso, mas também

\footnotetext{
${ }^{3}$ O livro ganhou o prêmio da Academia das Ciências concedido no mesmo ano para o melhor trabalho que versasse sobre as ideias de Eça, por ocasião do centenário do nascimento do autor em 1945.

${ }^{4}$ SARAIVA, 1950, p. 36 - 37. Mister mencionar que Maria Filomena MÓNICA (2001, p. 36), em sua recente e profícua biografia sobre Eça, confirma e ressalta esses ideais vivenciados pelo escritor e seus amigos no período de estudos em Coimbra.
} 
toda a história política e social, inclusive aquilo que se esperava do futuro: era a certeza da plenitude do ser humano, do humanismo absoluto, da consciência plena e da moral elevada. Tudo o que se realizaria na Natureza, todas as forças internas de organização de uma matéria, é a mesma força que o Homem poderia expressar em si mesmo, em sua própria Consciência.

Saraiva recorre principalmente às primeiras ficções de Eça para referendar suas proposições, desta forma, muitos serão os exemplos retirados das Prosas bárbaras, obra publicada em 1903 e em que estão coligidos os primeiros contos de Eça, escritos entre 1866 e 1867.

Aqui talvez se apresente um dos problemas da tese de Saraiva: os outros escritos de Eça, nos quais a religião figura, são pouco ou nada analisados. A opção do crítico fez com que sua tese ficasse mais circunscrita às obras da primeira e da segunda fase de Eça 5, excluindo os escritos derradeiros, para os quais são feitos raros e rápidos comentários, sem análise profunda.

O próprio título do livro, no entanto, revela o que Saraiva tentará desenvolver ao longo de seu estudo. Ele pretende abarcar todas "as ideias de Eça de Queirós”. De fato, desde a fase inicial da produção queirosiana, a ideia de que é necessário ao homem o regresso para a vida simples do campo em oposição à agitação da vida urbana já vigora e não será uma exclusividade da última fase de produção do autor como em $A$ cidade $e$ as serras (1901), por exemplo. Nos primeiros escritos, contudo, a natureza possui contornos divinizados, uma Natureza sagrada e panteísta detentora de toda bondade, paz e sabedoria. O crítico não faz essa ressalva, se atendo somente aos textos iniciais, como já dissemos, fato que leva o leitor de seu estudo a acreditar que a religiosidade expressa nas obras de Eça resume-se na tese da Natureza "divinizada" exposta acima, o que não se confirma quando partimos para a análise das obras da última fase, como demonstramos em estudo recente ${ }^{6}$.

A tese de Saraiva realmente procede para os escritos da primeira fase, pois eles

\footnotetext{
${ }^{5}$ Utilizaremos neste trabalho a noção de "fases literárias" para a compreensão da obra completa de Eça de Queirós a partir do que denomina MOISÉS (1999, p. 194 - 197): A primeira fase começa com os artigos e crônicas publicados entre 1866 e 1867 na Gazeta de Portugal, coligidos postumamente no volume Prosas bárbaras e termina em 1875 com publicação da versão definitiva de $O$ crime do padre Amaro que vinha sendo escrito desde 1871. A segunda fase principia com a publicação de $O$ primo Basílio (1878) e vai até o Os Maias (1888) - é a fase onde são publicadas as obras de maior virulência e crítica ferina. A terceira e última fase corresponde aos escritos posteriores a 1888 e que vão até a morte do escritor em 1900.

${ }^{6}$ NERY, 2005.
} 
revelam insistentemente que o afastamento dessa Natureza superior causaria a dor, a tristeza, a frustração no homem e todo o esforço para manter-se bem fora dessa Natureza-mãe seria vão. Desta forma, o bem completo só seria realmente encontrado no estado de Inconsciência humana?

De acordo com Saraiva, para o Eça das Prosas bárbaras a Consciência traria apenas indisposição. É por isso que somente com a morte, com o corpo humano voltando a terra, que toda a paz, o sossego e o descanso são presenteados ao ser humano: "Para Eça a alma e a Natureza, isto é, o Consciente e o Inconsciente constituem uma dualidade e opõem-se como o Mal e o Bem"».

"Os mortos", um dos textos encontrados nas Prosas bárbaras, pode ser tido como exemplo desse pensamento. A ideia da morte como pacificadora e condutora à comunhão plena com a Natureza é amplamente veiculada. O texto inicia com uma contextualização temporal: "Ontem foi o dia dos mortos" ${ }^{10}$ e logo afirma o principal mote que percorrerá toda a narrativa do início ao fim: "Os mortos são felizes".

É relatado o sofrimento vão daqueles que ainda vivem e que julgam que com a morte tudo acaba, pois, justamente com a vida que o homem é infeliz, constantemente sofrendo agruras: "a sua carne sofreu, empalideceu com os medos, emagreceu com as febres, engelhou-se com os frios" "1. Quando há o falecimento, a vida renasce com a Natureza "mas agora (sua carne) anda, repousada e sã, pelas frescas vegetações, pelos frutos coloridos, na luz selvagem e vital do sol, nos átomos da noite constelada e suave". Portanto:

(...) os mortos são felizes, porque andam longe da forma humana, onde há o mal, pela grande natureza Santa, onde há o bem, na pureza, na serenidade, na fecundidade, na força. Bem aventurados os que vão para debaixo do chão, porque vão para uma transfiguração sagrada ${ }^{12}$.

De fato Eça soube exprimir de forma exemplar, nesta literatura inicial, os

\footnotetext{
${ }^{7}$ Poderíamos ser levados a pensar, dado a semelhança da teoria, no pessimismo de Schopenhauer. Todavia, o próprio António José Saraiva apressa-se em alertar que Eça não conheceu este filósofo. Na verdade, em artigo publicado em homenagem a memória de Antero de Quental nas Notas Contemporâneas o próprio Eça relata referindo-se ao período de estudos em Coimbra: "Ninguém, então, do Reno para cá, lera ainda Schopenhauer" (QUEIRÓS, 1945b, p. 270).

${ }^{8}$ SARAIVA, 1950, p. 39.

${ }^{9}$ Doravante OM nas referências de citações.

${ }^{10} \mathrm{OM}$, p. 110.

${ }^{11}$ OM, p. 111.

${ }^{12} \mathrm{OM}$, p. 113.
} 
princípios "humanitários" lembrados constantemente por Saraiva. Em todos os textos "fantásticos" das Prosas bárbaras temos um Homem que se demonstra derivado da Natureza, dependente de uma força inexplicável e misteriosa. O Homem por si próprio parece estar afastado dessa força, e a causa para este afastamento é a própria vida, a alma.

Para Saraiva é neste ponto que o pensamento do jovem Eça destoa completamente do que diriam Victor Hugo, Michelet ou Antero de Quental, alguns daqueles que teriam sido referência para o escritor neste sentido, pois, para esses, o bem é a plenitude da Consciência, para a qual tende toda natureza e toda história num esforço incessante. Já para Eça não haveria oposição entre a Natureza e o Homem, o que fazia o autor propor, como alternativa ao panteísmo evolucionista de suas referências, um vago naturalismo. Saraiva explicita que isso não constituía uma contraposição, simplesmente Eça não teria conhecido a fundo as proposições dos idealizadores da referida teoria em que Antero de Quental tanto se apoiou ${ }^{13}$.

Percebemos aqui uma perspectiva redutora de António José Saraiva para a análise sobre as referências de Eça. É mais uma sinalização de que o crítico não supõe uma liberdade criadora para o escritor, pois, indiretamente, ele aponta para o fato de que a contraposição explicitada por Eça com relação à Natureza deu-se somente porque o escritor não estudou detidamente aquilo que Antero estudava.

O misticismo naturalista do embate entre Homem e Natureza permeara muitos contos das Prosas, como bem analisa o crítico, porém, já nestes escritos, reconhecemos uma característica de Eça frente à religiosidade que se fará presente até a última fase: a dialética com que trabalhará com tal tema em suas obras. $\mathrm{Na}$ mesma coletânea de textos na qual encontramos "Os mortos" e a pacificadora noção da comunhão com a Natureza, encontramos uma outra narrativa intitulada "Entre a Neve"14, na qual ficará nítida a problematização dessa concepção apaziguadora.

A narrativa conta a história de um lenhador que vai até uma floresta para cortar árvores, mas a natureza sorrateira o aprisiona e a neve se encarrega de matá-lo.

Para o leitor mais desavisado surge uma incoerência a partir da configuração da ação. O lenhador e sua família eram pobres, passavam fome, enfim, viviam na mais profunda miséria "Ali vivia aquela família transida dos frios, emagrecida das fomes,

\footnotetext{
${ }^{13}$ Cf. SARAIVA, 1950, p. 40.

${ }^{14}$ Doravante EN nas referências de citações.
} 
diante da neve e dos invernos (...)" ${ }^{" 15}$. Desprovidos de tudo não tinham nem a atenção de Deus que "agasalhado ao calor dos seus paraísos e das suas estrelas"16 parecia ter esquecido aquela família deixando-a a sua própria sorte.

Quando o lenhador vai à floresta em busca de lenha e do sustento para sua família, é apresentada uma contraposição que perpassará toda a narrativa: a fragilidade do homem versus a força da floresta. Essa incompatibilidade e descontinuidade são perceptíveis do início ao fim da narrativa. Enquanto há poucas linhas havia se apresentado a condição miserável na qual vivia o lenhador, a partir de agora avulta-se em sua frente a poderosa floresta:

Os velhos carvalhos violentos e proféticos, os choupos desfalecidos, os castanheiros ruidosos, os olmos gigantescos, as ramagens e os silvados eriçados onde o vento brada aflito, todas aquelas verduras vivas e sãs que cantam ao sol, no empoeiramento da luz crua - toda aquela sombria Diana esguedelhada, que se chama a floresta, dormia sob as opressões da neve, triste, silenciosa, estóica e soberba ${ }^{17}$.

Desta forma, quando o lenhador desfere contra um tronco as machadadas que fariam ele e sua família sobreviverem ao frio e à fome, ele sente, ao mesmo tempo, que mata vidas para salvar outras. E mesmo com toda a sua humildade e pela boa causa que fazia aquilo, fica patente ao leitor que o lenhador realizava uma profanação daquela Natureza sagrada e portentosa. Todo o ambiente compadece-se da "dor" do carvalho:

O lenhador atirou o machado contra o tronco do carvalho - e toda a árvore imensa ficou tomada de vibrações dolorosas: e as suas ramagens estenderam-se caídas, sem vida e sem forças, pelo tronco, como para se verem morrer sem gemidos, num silêncio soberbo e selvagem. O sol veio lívido, mole, desfalecido, sem força, sem vitalidade, sem ascensão flamejante e sagrada, entre névoas arrastadas, entre esvaecimentos lúgubres de nuvens. Começavam a esvoaçar os pássaros, piando tristemente ${ }^{18}$.

Como se vê, todos os outros elementos naturais começaram a manifestar seu desgosto pelo lenhador após aquele ato. E o protagonista do conto começa a ser

\footnotetext{
${ }^{15}$ EN, p. 100.

${ }^{16} \mathrm{EN}, \mathrm{p} .101$.

${ }^{17}$ EN, p. 103.

${ }^{18}$ EN, p. 104.
} 
mostrado de uma outra forma, não mais como um sofredor, mas como aquele que faz sofrer em nome de seus interesses ${ }^{19}$.

Todos os acontecimentos que ocorrem depois do "pecado" cometido contra a "mãe-natureza" prefiguram a morte e a forma dificultosa através da qual se dará a comunhão do lenhador com a Natureza. A narração valoriza os traços de miserabilidade do homem. Ao tentar carregar toda a ramagem e lenha que tinha conseguido, o lenhador cai desfalecido e daquele lugar não consegue levantar mais, todas a cenas posteriores mostram novamente a fraqueza dele frente à força da Natureza. Já quase agonizante o lenhador recorre a Jesus, mas a resposta que recebe é somente um tumular silêncio que envolve toda a floresta. E do céu, de onde poderia vir sua salvação, ironicamente, vem a neve que acabará por matá-lo. :

\begin{abstract}
Então, vendo em redor a floresta solitária e negra, a amontoação crescente das sombras, o esvaenecimento lívido dos últimos ramos, as atitudes tenebrosas, as corcovas nocturnas das raízes, sentindo ao longe o uivo dos lobos e por cima da cabeça o esvoaçar dos corvos, estirou-se de bruços e bradou, na noite, sob a neve e o ruído dos ramos: - Jesus! E toda a floresta ficou silenciosa, indiferente, soberba; os corvos voaram gritando; ele caiu, fraco, desalentado, roto, agonizante, mascerado; o céu sagrado, o céu consolador cuspia neve sobre aquela carne miserável ${ }^{20}$.
\end{abstract}

Se é somente na Natureza que o homem se completa e não é necessário transcendê-la, mas na própria imanência pode-se contemplar a plenitude do ser - noção que podemos depreender de "Os mortos" - em "Entre a neve" encontramos um contraponto. Indiretamente, o conto transparece a mensagem de que, para haver uma perfeita integração, é necessário que o homem tenha o mínimo de condição social para sobreviver, ou seja, o desequilíbrio social redunda em um desequilíbrio natural. Para ter uma perfeita comunhão com o solo, com a Natureza, o homem precisa estar dignamente integrado com o ambiente ainda enquanto vive.

$\mathrm{Na}$ citação acima observamos que a morte do lenhador decorre de sua

${ }^{19}$ Este trecho é muito parecido com o conto Frei Genebro, publicado em 1894, durante a última fase de Eça. Curiosamente a história de Genebro assemelha-se muito com a do lenhador. Toda a sua vida era exemplo de humildade, bondade e compaixão, a sua santidade era certa. Porém, logo após a sua morte, Genebro é condenado ao purgatório e o principal responsável pela condenação foi o fato de ele ter decepado a perna de um porco para saciar a gula de um confrade amigo seu . O ato ilustrado quase como sanguinário revelou a verdadeira face de Genebro. (Cf. NERY, Antonio Augusto. O Intrigante Frei Genebro. In: Anais do XIV CELLIP. Maringá, 2003).

${ }^{20} \mathrm{EN}$, p. $107 ; 108$. 
"maldade", ocasionada por suas misérias e necessidades. Sua comunhão com os elementos naturais se dá não da forma pacífica como a relatada em "Os mortos", mas conflitante, "agonizante" ante uma Natureza "agressiva".

António José Saraiva não aponta essas divergências em relação às próprias ressalvas sugeridas por Eça a ideais veiculados em escritos de um mesmo período, ou seja, o crítico não expõe a figuração ambígua da natureza, realizando uma leitura parcial neste sentido.

Em "A morte de Jesus", um outro conto das Prosas bárbaras, assim como em “Os mortos" veremos que toda a ambientação demonstrará a comunhão e a integração perfeita, precisa, entre o homem e a "mãe natureza", diferente do lenhador oprimido de "Entre a neve", que luta com os elementos naturais porque, justamente, não possui a pacificação material e uma vida social plena.

Devemos ressaltar que a preocupação de Eça com a realização material das mínimas condições dignas de sobrevivência acompanhará o autor desde esses primeiros escritos até os últimos ${ }^{21}$. Caso não atentemos para essas ressalvas que o próprio autor faz ao "naturalismo místico", e que aqui apontamos, podemos ser levados a crer, como muitos críticos foram, que Eça se transformou em reacionário ao deixar a crítica virulenta em segundo plano e dar prioridade para preocupações mais humanitárias, quando, verdadeiramente, na última fase encontramos apenas a intensificação dessas ideias sociais já presentes aqui, e que parecem sempre estar intimamente ligadas à temática religiosa.

A nosso ver a tese de Saraiva procede, porém, não para explicar suficientemente toda a temática religiosa presente nas obras de Eça, como pretende o autor. A explicação da tese da Natureza permanece presente nos romances de Eça desde os escritos iniciais até a segunda fase. Todavia, a última fase da produção do escritor, que vai desde a publicação de Os Maias em 1888 até sua morte, não é facilmente explicada através da tese de Saraiva.

António José Saraiva postula que na última fase ${ }^{22}$ de Eça "o homem reingressa no segundo plano" ${ }^{23}$. Contrariando a crítica ferina tecida contra a sociedade em obras como O crime do padre Amaro (1871), o autor das Vidas de santos (1912) teria

\footnotetext{
${ }^{21}$ Cf. NERY, 2005.

${ }^{22}$ Todos os escritos posteriores à publicação de Os Maias (1888).

${ }^{23}$ SARAIVA, 1946, p.129.
} 
abandonado o ponto de vista sociológico e retrocedido "àquele naturalismo bucolista que notamos nas Prosas bárbaras” (1903). Na verdade, o crítico conclui que, tal qual Fradique Mendes, Eça evadiu-se da realidade para encontrar as respostas das crises Sociais $^{24}$.

É justamente na análise das obras posteriores a 1890 que a crítica de Saraiva torna-se problemática. Ao tecer a conclusão acima, o autor concorda com os críticos que desvalorizam os escritos derradeiros de Eça em comparação com as "grandes obras" como O crime do padre Amaro (1871), O primo Basílio (1886) e Os Maias (1888), bem como supõe que a religiosidade retoma a "teologia" natural da primeira fase.

Diferente da postura adotada frente à religiosidade nos primeiros escritos de Eça, Saraiva não se detém muito sobre as importantes figurações deste tema nas últimas obras, que acabam sendo analisadas como devaneios místicos, ou "uma evasão da realidade". Talvez porque, como analisamos, para ele toda a religião presente em Eça resumir-se-ia na tese da Natureza mística.

Como já comprovamos ${ }^{25}$ a temática religiosa na prosa final queirosiana vai além de uma sugestão evacionista ou reacionária e diferencia-se consideravelmente da tese naturalista desenvolvida por Saraiva. Somos levados a afirmar que ela estará presente com a mesma intensidade - por vezes sobrelevando-se - com que figura nos escritos da primeira e da segunda fases, pois além da ficção, encontramos diversas reflexões acerca da religião nas crônicas e artigos que o autor escreveu depois de 1890.

\section{Referências Bibliográficas:}

MÓNICA, Maria Filomena. Eça de Queirós. 4ª ed. Lisboa: Quetzal Editores, 2001.

MOISÉS, Massaud. A literatura portuguesa. São Paulo: Cultrix, 1999.

NERY, Antonio Augusto. Santidade e humanidade: aspectos da temática religiosa em obras de Eça de Queirós. Dissertação de Mestrado. Curitiba, UFPR, 2005.

QUEIRÓS, Eça de. __ _ _. Prosas bárbaras. Porto: Lello e Irmãos, 1945a. Notas contemporâneas. Porto: Lello e Irmãos, 1945 b.

SARAIVA, António José. As Ideias de Eça de Queiroz. Lisboa: Livraria Bertrand, 1950

\footnotetext{
${ }^{24}$ Propositalmente o último capítulo do livro de Saraiva em que o autor desenvolve uma conclusão e analisa os últimos escritos de Eça é intitulado "O Fradiquismo".

${ }^{25}$ NERY, 2005.
} 
